\title{
Isolated bilateral ectopic microspherophakia
}

\author{
André Omgbwa Eballe' \\ Godefroy Koki ${ }^{2}$ \\ Emilienne Epée ${ }^{2}$ \\ Didier Owono ${ }^{2}$ \\ Lucienne Bella Asumpta ${ }^{2}$ \\ Côme Ebana Mvogo² \\ 'Faculty of Medicine and \\ Pharmaceuticals Sciences, University \\ of Douala, Cameroon; ${ }^{2}$ Faculty of \\ Medicine and Biomedical Sciences, \\ University of Yaoundé, Cameroon
}

Correspondence: André Omgbwa Eballe Department of Ophthalmology,

Gynaeco-Obstetric and Pediatric Hospital of Yaoundé, PO Box 4362, Yaoundé,

Cameroon

Tel +64 23799654468

Fax +64 23722212430

Email andyeballe@gmail.com

\author{
This article was published in the following Dove Press journal: \\ Clinical Optometry \\ 5 February 2010 \\ Number of times this article has been viewed
}

\begin{abstract}
Summary: An eight-year-old school girl presented to us with a bilateral ectopic microspherophakia. She was surgically managed in the ophthalmology unit of the GynaecoObstetric and Pediatric Hospital of Yaoundé in Cameroon. The postoperative follow up was uneventful, and the patient returned to school with a best corrected visual acuity of 4/10 in both eyes to the great satisfaction of her parents.
\end{abstract}

Keywords: ectopic, microspherophakia, surgery

\section{Introduction}

Microspherophakia is a condition where both the shape and size of the lens are abnormal; the lens being spherical and abnormally small. This could be regarded as a simple arrest of lens development between the fifth and sixth month of intrauterine life. Other authors explain microspherophakia as a disorder in the length of the zonular fibers eliminating the zonular traction on the lens. ${ }^{1}$ Ectopia lentis for example presents as a displacement of the lens associated with other primitive disorders of the zonular fibers. The lens usually remains clear but may become opaque. Microspherophakia can be isolated or associated with other ocular or systemic manifestations, with known etiology or not..$^{2-4}$ We present a clinical case observed in the ophthalmology unit of the Gynaeco-Obstetric and Pediatric Hospital of Yaoundé.

\section{Case report}

The paper describes an 8-year-old girl from South Cameroon who is the first born in a family of four to non-consanguineous parents. She was brought to the outpatients clinic by her parents on February 5, 2009, complaining of bilateral decreased visual acuity and monocular diplopia. These symptoms had slowly and progressively become worsened over the years. The personal and family histories did not suggest the condition was a familial trait.

The visual acuity, with best correction (-6.00 diopter sphere (DS) in both eyes) was $1 / 20$ using the Snellen chart. The near vision with the Parinaud scale was estimated at P4. An esotropia of 15 prism diopter of the left eye was noted.

Slit lamp examination of both eyes revealed clear corneas, round-shaped and centered pupils reactive to light, marked iridodonesis and phacodonesis. After pupillary dilation, we noticed both lenses were clear and ectopic in superotemporal position. The lens equator was visible within the pupil. Examination of the aphakic crescent of the pupillary area revealed zonules that were stretched though unbroken.

submit your manuscript | www.dovepress.com 
An increased curvature of the anterior aspect of the lenses was noted. Indirect fundoscopy revealed diffused retinal atrophy together with disc diversion although the vascular bed appeared normal.

The horizontal and vertical dimensions of both corneas were $11.75 \mathrm{~mm}$ and $11.50 \mathrm{~mm}$ respectively. The central corneal thickness of both the right and left eyes were determined, using an ultrasonic pachymeter, as $547 \mu \mathrm{m}$ and $533 \mu \mathrm{m}$ respectively. Examination of the anterior chamber angle using a Goldman 3-mirror gonioscope revealed an open angle in the four quadrants measuring grade 4 (Shaffer system). The intraocular pressure (IOP) measured with a pulsed air tonometer was $11 \mathrm{~mm} \mathrm{Hg}$ in both eyes. Autorefractometric examination of the phakic region of the pupillary area was $-6 \mathrm{DS}$ in both eyes. This could not be quantified in the aphakic region. A-Scan biometry revealed that the axial length of both eyeballs was $24.5 \mathrm{~mm}$.

To look for associated systemic disorders a general assessment was performed, in the pediatric unit of the same hospital, with an emphasis on cardiovascular and skeletal systems. No general pathology was identified. The mental condition of the child was normal. A complete ophthalmological examination of the parents and siblings of the girl were found to be normal.

From these findings, our patient was diagnosed with having isolated bilateral ectopia lentis requiring immediate care. Subjective refraction with -6 DS did not improve the visual acuity greater than was initially diagnosed, ie, 1/20 in both eyes. Given this failure, it was decided to undertake surgical correction with an intracapsular extraction of both crystalline lenses, under general anesthesia to avoid dislocation of the lens in the anterior chamber or in the vitreous, to restore a satisfactory visual acuity with treatment of amblyopia through new optical correction. After receiving information about the risks of such surgery the parents signed a release before the operation.

After a corneolimbal incision from the 11-o'clock to 1-o'clock meridians, viscoelastic solution was injected into the anterior chamber together with alpha chymotrypsin. Extraction of the lens with a Snellen loop (as not having a cryoprobe in our technical platform) was performed. Peripheral iridectomy was undertaken at a 12-o'clock meridian. Wound closure was achieved with 4 hidden nodes using 10/0 black silk sutures. A subconjunctival injection of dexamethasone and gentamicin $(0.5 \mathrm{~mL})$ was undertaken at the end of surgery before both eyes were padded.

Postoperative examination of the lenses (Figure 1) found them both to be ectopic, clear and spherical, measuring $5 \mathrm{~mm}$ and $4.75 \mathrm{~mm}$ in the equatorial and anteroposterior meridian respectively.

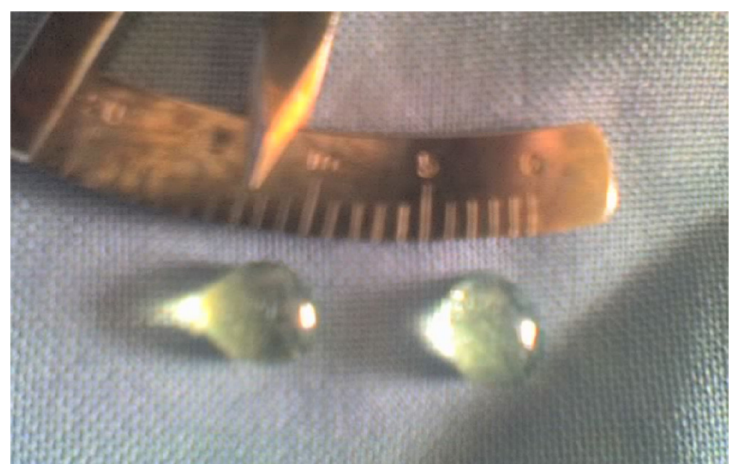

Figure I Both left and right lenses after surgery.

Post operative patient care was uneventful and eight weeks after, autorefraction was +4.25 DS in both eyes. No astigmatism was noted. IOP was $11 \mathrm{~mm} \mathrm{Hg}$ in both eyes, the best corrected visual acuity was $4 / 10$ in both eyes using the Snellen chart.

\section{Discussion}

Isolated microspherophakia is a rare condition. It is most often hereditary or familial or integrated into a general malformation syndrome. ${ }^{2-5}$ Several authors have reported that this condition is bilateral in the majority of cases and affects both sexes equally. ${ }^{1,6-8}$ However, unilateral microspherophakia has been reported by Cordiale in $1901 .^{9}$ The disease is most often diagnosed during early childhood, ${ }^{1,6-9}$ often at primary school, as is the case of our patient. The problem of poor sightedness at this age, noticed by both parents and teachers, was the sign that encouraged consultation in our unit.

Microspherophakia is usually associated with axial and index myopia; ${ }^{8}$ as in this case where autorefractometric examination of both eyes revealed simple myopia with -6 DS and low visual acuity $(1 / 20)$ in both eyes. Such an ocular pathology hinders normal schooling and educational progress. High IOP in microspherophakia is rare - in our patient IOP was normal, although when present IOP elevation usually results from anterior chamber angle abnormalities, or pupillary block due to anterior dislocation of the lens. In the latter case, glaucoma is affected by miotics and yet disappears with mydriatics. ${ }^{8,10}$

Familial microspherophakia, generally not associated with other systemic malformations, is inherited as an autosomal recessive trait and associated with ectopia lentis where the lens is most frequently displaced upwards. ${ }^{3,4}$ With our patient the manifestation of this condition is sporadic or possibly familial as no previous case was identified in the immediate family.

Microspherophakia may also occur in other inherited or familial affections, ${ }^{3,8,9}$ such as Marfan syndrome or Weill-Marchesani syndrome..$^{2-4}$ Marfan syndrome is an 
autosomal dominant connective tissue disease, $15 \%$ of which is sporadic, with skeletal, cardiac and ocular manifestations. The condition is characterized by sufferers being typically tall with disproportionately long limbs and fingers (macroskely), kyphoskoliosis, prolapsed mitral valve, aortic dissection, and bilateral superotemporal ectopia lentis. Weill-Marshesani syndrome is also a congenital disorder of connective tissue transmitted as an autosomal dominant or recessive trait and characterized by brachymorphic features (short stature, brachycephaly, brachydactily), reduced joint mobility, lenticular myopia and microspherophakia with loose zonules. As there were no other signs or symptoms suggestive of these syndromes we concluded that this case is an isolated bilateral ectopic microspherophakia.

In managing microspherophakia, many authors agree that asymptomatic uncomplicated isolated microspherophakia should be treated with optical correction, ${ }^{8,11}$ where multifocal contact lenses or spectacles are used to compensate for weakness in accommodation due to stretching of zonula fibers. ${ }^{8}$ In cases where the lens is subluxated, in danger of becoming dislocated, or if microspherophakia is symptomatic then surgical intervention is indicated, as lenticular extraction will prevent complete lens dislocation and IOP elevation in addition to reducing myopia. ${ }^{8}$ With this patient surgical intervention was indicated by very poor preoperative visual acuity. Postsurgical visual acuity, with best optical correction, only improved to $4 / 10$. Such a poor outcome resulted from moderate amblyopia, sequelae of late diagnosis and delayed treatment.

Phacoemulsification with the implantation of a foldable intraocular lens (IOL) mounted on a capsular tension ring (CTR) is a surgical technique that has been used by some surgeons, ${ }^{7}$ for others this technique is more effective for post traumatic lenticular subluxations of less than $160^{\circ}$ because of the remaining of zonula fiber being normal and the risk of IOL decentration is low. However this may not be appropriate in cases of microspherophakia which are most often associated with progressive zonular disorders. ${ }^{12}$ It is for this reason, together with the unavailability of CTR and lack effective phacoemulsification instrumentation, that we did not opt for an intraocular lens implantation. The bilateral surgical management that was performed was seen as best practice by the parents who did not want their child to undergo general anesthesia twice for the same condition having understood the increased risks of infection and inflammation that might ensue. Fortunately in this case the postoperative recovery was uneventful.

The prognosis of surgically treated microspherophakia is known to be poor as visual acuity decreases with time for various reasons with many of these patients becoming blind from glaucoma or retinal detachment in later life. ${ }^{8,13}$ In these cases counseling should be undertaken to plan for further social rehabilitation.

\section{Conclusion}

Microspherophakia and ectopia lentis are rare conditions usually associated with multiple malformation syndromes physicians should always look for and are an indication for multidisciplinary management. In this reported case regular monitoring was recommended with ophthalmologic assessment each year for early detection of any possible complications.

\section{References}

1. Duke-Elder Sir WS. System of ophthalmology vol.III. Normal and abnormal development Part 2 Congenital deformities. St Louis: CV Mosby Co; 1963. pp. 694-696.

2. Brown NP, Bron AJ. Lens disorders: A clinical manual of cataract diagnosis. London: Butterworth Heinemann Publishers; 1966. pp. 86-90.

3. Johnson VP, Grayson M, Christian JC. Dominant microspherophakia. Arch Opthalmol. 1971;85:534-542.

4. Kanski JJ. Clinical Ophthalmology. 2nd ed. Oxford: Butterworth Heinemann, 1989

5. Apple DJ, Rabb MF. Ocular pathology. St. Louis: Mosby Inc; 1991. p. 124.

6. Hudelo J. Ocular manifestations of cystinosis within the framework of familial nephropathies. Bulletin société d'ophtalmologie de France. 1966;66(1):49

7. Lee DA, Higginbitham EJ. Clinical guide to comprehensive ophthalmology. New York: Theime Medical Publishers; 1999. p. 15.

8. Michaud C. Microspherophakia. Can J Ophthamol. 1970;5(3):252-254.

9. Cordiale M. Un cas de microphakie. Ann Oculist Paris. 1901;126:346-353.

10. Khokhar S, Pangtey MS, Sony S, Panda S. Phacoemulsification in a case of microspherophakia. J Cataract Refract Surg. 2003;29:845-847.

11. Dénise Goddé-Jolly, Jean Louis Duffier. Ophtalmologie pédiatrique. Paris: Elsévier Masson; 1992. pp. 1999-2000.

12. Gerasimos TH, Georgopoulos, Dimitrios Papaconstantinou, Ilias Georgalas, Chrysanthi N, et al. Management of large traumatic zonular dialysis with phacoemulsification and IOL implantation using the capsular tension ring. Acta Ophthalmol Scand. 2007:85(6):653-657.

13. Rufina Tin-Yan Chan, Barry Collin H. Microspherophakia. Clin Exp Optom. 2002;85(5):294-299.
Clinical Optometry

\section{Publish your work in this journal}

Clinical Optometry is an international, peer-reviewed, open access journal publishing original research, basic science, clinical and epidemiological studies, reviews and evaluations on clinical optometry. All aspects of patient care are addressed within the journal as well as the practice of optometry including economic and business analyses. Basic and clinical

\section{Dovepress}

research papers are published that cover all aspects of optics, refraction and its application to the theory and practice of optometry. The manuscript management system is completely online and includes a very quick and fair peer-review system, which is all easy to use. Visit http://www.dovepress. com/testimonials.php to read real quotes from published authors. 